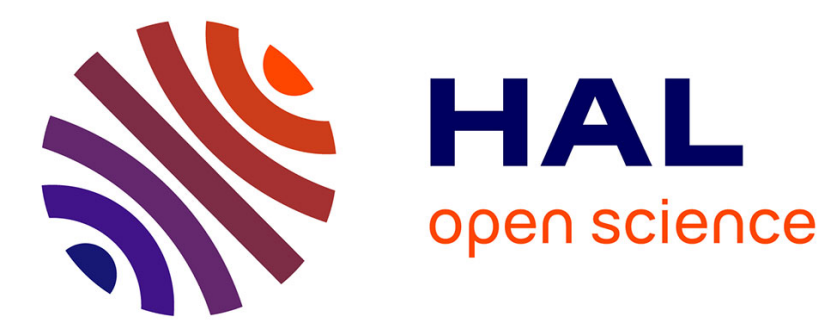

\title{
Statistical thermodynamics of ordering systems
}

\author{
L. Nobili, A. del Prete, U. Ducati, P. Cavallotti
}

\section{To cite this version:}

L. Nobili, A. del Prete, U. Ducati, P. Cavallotti. Statistical thermodynamics of ordering systems. Journal de Physique IV Proceedings, 1993, 03 (C7), pp.C7-2047-C7-2050. 10.1051/jp4:19937327 . jpa-00251973

\section{HAL Id: jpa-00251973 https://hal.science/jpa-00251973}

Submitted on 1 Jan 1993

HAL is a multi-disciplinary open access archive for the deposit and dissemination of scientific research documents, whether they are published or not. The documents may come from teaching and research institutions in France or abroad, or from public or private research centers.
L'archive ouverte pluridisciplinaire HAL, est destinée au dépôt et à la diffusion de documents scientifiques de niveau recherche, publiés ou non, émanant des établissements d'enseignement et de recherche français ou étrangers, des laboratoires publics ou privés. 


\title{
Statistical thermodynamics of ordering systems
}

\author{
L. NOBILI, A. DEL PRETE, U. DUCATI and P.L. CAVALLOTTI
}

Politecnico di Milano, Dipartimento di Chimica Fisica Applicata, P.zza L. da Vinci 32, 20133 Milano,
Italy

\section{ABSTRACT}

A statistical thermodynamic approximation for cooperative phenomena in Ising and Heisemberg systems has been developed. Description of order-disorder transformation in alloys as well as evaluation of the magnetic contribution for the free energy of ferromagnets is provided with this approach.

The constant coupling approximation is improved by introducing a second pairs reactions after averaging atomic groups, on the analogy of block construction in renormalization group techniques. Temperature variation after renormalizing is taken into account by two suitable temperature functions. An analytic expression for the system free energy is obtained which gives well approximate thermodynamic quantities (order parameter, internal energy, specific heat). In particular, the critical behaviour is properly described, with accurate thermodynamic quantities and right exponents.

This approach has been applied to real system, showing what are the differences with ideal Ising system. In orderdisorder alloys like $\beta$-brass, order parameter and specific heat as a function of temperature are obtained and ordering phenomena are discussed.

\section{INTRODUCTION}

Properties of ordering systems are involved in development of many materials, the applications of which range from magnetic components to high temperature alloys. Quantitative evaluation of free energy of these systems is valuable in order to describe the evolution of atomic ordering with temperature and to give an interpretation of phase equilibria.

It has been previously shown [1-3] that it is possible, by improving the well known Quasi Chemical (QC) approximation [4], to obtain critical quantities for Ising systems very close to exact or best known values, with a great improvement with respect to other proposed statistical thermodynamic approximations.

The configurational free energy function of ordering $\beta$-brass has been obtained by applying this approach and the thermodynamic behaviour of this system is discussed.

\section{IMPROVED QUASI CHEMICAL APPROXIMATION}

Ordering for Ising systems is described in the $\mathrm{QC}$ approximation by considering a $\mathrm{QC}$ reaction between atomic pairs:

$$
\mathrm{AA}+\mathrm{BB}=2 \cdot \mathrm{AB}
$$

with an equilibrium constant $\mathrm{K}_{\mathrm{eq}}=\exp \left(\Delta \varepsilon / \mathrm{k}_{\mathrm{B}} \mathrm{T}\right)=\exp \left(-2 \mathrm{~K}_{\mathrm{C}} / \tau\right)$, where $\Delta \varepsilon$ is the interaction energy for neighbour pairs, $\mathrm{k}_{\mathrm{B}}$ the Boltzmann constant, $\mathrm{T}=\tau \cdot \mathrm{T}_{\mathrm{C}}$ the absolute temperature and $\mathrm{K}_{\mathrm{C}}=-\Delta \varepsilon /\left(2 \mathrm{k}_{\mathrm{B}} \mathrm{T}_{\mathrm{C}}\right)$ is the critical parameter.

The number of unlike pairs $\left(\mathrm{N}_{\mathrm{AB}}\right)$ is calculated by the equilibrium constant as:

$$
\mathrm{N}_{\mathrm{AB}}=2 \mathrm{~N}_{\mathrm{S}}\left(1-\eta^{2}\right) /(4(1+\beta))=\mathrm{N}_{\mathrm{MFA}} /(1+\beta)
$$

where $N_{M F A}$ is the number of unlike pairs in the mean field approximation and $\beta$ is given by

$$
\beta=\left[1+\left(1-\eta^{2}\right)\left(1 / \mathrm{K}_{\mathrm{eq}}{ }^{-1}\right)\right]^{1 / 2},
$$

$z$ is the coordination number, $N_{S}$ is the number of lattice sites and the order parameter $\eta=2 N_{A} / N-1$ represents the distribution of the atoms of one species on the two sublattices. 
Interaction between atomic groups is taken into account in the IQC approximation, by introducing a second QC equilibrium. After averaging $\mathbf{n}$ atom interactions, a new lattice of fixed atoms (with coordination number $\mathrm{z}_{\mathrm{I}}$ ) is obtained and a $\mathrm{QC}$ reaction between atomic groups is considered:

The number of unlike pairs is

$$
(\mathrm{AA}+\mathrm{BB}=2 \cdot \mathrm{AB})_{\mathrm{I}} \quad \mathrm{K}_{\mathrm{eq}}=\exp \left(-4 \mathrm{~K}_{\mathrm{C}} / \rho\right)
$$

$$
\begin{aligned}
& \mathrm{N}_{\mathrm{AB}}^{\mathrm{I}}=\left(\mathrm{z}_{\mathrm{I}} / \mathrm{n}\right) \cdot \mathrm{N}_{\mathrm{S}} \cdot\left(1-\eta_{\mathrm{I}}^{2}\right) /\left[4\left(1+\beta_{\mathrm{I}}\right)\right] \\
& \text { with } \quad \beta_{I}=\left[1+\left(1-\eta_{I^{2}}\right)\left(1 / K_{\text {eq }}{ }^{2}-1\right)\right]^{1 / 2} ; \quad ; \quad \eta_{I}=\eta /(\varphi)^{i / 2}
\end{aligned}
$$

$\varphi(\tau)$ is a temperature function taking into account the change of the order parameter after averaging and the relative importance of the second QC reaction. Another correction factor, $\rho(\tau)$, is introduced, which allows temperaturedependent interaction energy to be considered; in $K_{\text {eq }}, \tau$ is replaced by $\rho(\tau)$ :

The configurational free energy function is given by

$$
\mathrm{K}_{\mathrm{eq}}=\exp \left(-2 \mathrm{~K}_{\mathrm{d}} / \rho\right)
$$

$$
\frac{F}{R T_{0}}=-\frac{z K_{c}}{4}+\frac{T}{2 \delta} \cdot\left[(2-z) \cdot\left(\ln \frac{1-\eta^{2}}{4}+\eta \cdot \ln \frac{1+\eta}{1-\eta}\right)+z \cdot\left(\ln \frac{\beta^{2}-\eta^{2}}{(1+\beta)^{2}}+\eta \cdot \ln \frac{\beta+\eta}{\beta-\eta}\right)+\frac{z_{I}}{n} \varphi \cdot\left(\ln \frac{\beta_{I}^{2}-\eta_{I}^{2}}{\left(1+\beta_{I}\right)^{2}}+\eta_{I} \cdot \ln \frac{\beta_{I}+\eta_{I}}{\beta_{I}-\eta_{I}}\right)\right]
$$

The order parameter $\eta$ as a function of temperature is calculated by making equal to zero the first derivative of $F_{C}$ with respect to $\eta$. The expressions of internal energy $(U)$ and specific heat $\left(C_{v}\right)$ are obtained by derivatives of $F_{c}$ with respect to $\eta$.

\section{CRITICAL BEHAVIOUR OF ISING SYSTEMS}

The critical parameter $K_{c}\left(K_{c}=\ln \beta_{c}\right)$ is determined by the condition that the second derivative of $F_{c}$ with respect to $\eta$ is null at the critical point $(\tau=1, \eta=0)$ :

$$
\partial^{2} \mathrm{~F} / \partial \eta^{2}=\mathrm{z} / \mathrm{B}_{\mathrm{c}}+\left(\mathrm{z}_{\mathrm{I}} / \mathrm{n}\right) / \mathrm{B}_{\mathrm{c}} \mathrm{c}^{2}-2-\mathrm{z}=0
$$

\begin{tabular}{|c|c|c|c|c|c|c|}
\hline $\begin{array}{l}\text { Lattice } \\
\mathrm{z} \\
\mathrm{z}_{\mathrm{j}} / \mathrm{n}\end{array}$ & $\begin{array}{l}\text { Square } \\
4 \\
2\end{array}$ & & $\begin{array}{l}\text { Body-ce } \\
8 \\
1 / 3\end{array}$ & d cubic & $\begin{array}{l}\text { Face-ce } \\
12 \\
1 / 3\end{array}$ & 1 cubic \\
\hline $\begin{array}{l}\mathrm{K}_{c} \\
-F_{c} / \mathrm{k}_{\mathrm{B}} \mathrm{T}_{c}\end{array}$ & $\begin{array}{l}\text { B.A. } \\
.88137 \\
.92969\end{array}$ & $\begin{array}{l}\text { IQC } \\
.88137 \\
.92976\end{array}$ & $\begin{array}{l}\text { B.A. } \\
.31492 \\
.7540 \\
\end{array}$ & $\begin{array}{l}\text { IQC } \\
.31756 \\
.7560 \\
\end{array}$ & $\begin{array}{l}\text { B.A. } \\
.20420 \\
.7418 \\
\end{array}$ & $\begin{array}{l}\text { IQC } \\
.20470 \\
.7405 \\
\end{array}$ \\
\hline
\end{tabular}

The critical free energy value is calculated from the expression reported above assuming a critical value for $\varphi: \varphi_{\mathrm{cr}}=$ 0.44 for $2 D$-iattices and $\varphi_{\mathrm{Cr}}=0.25$ for 3-D lattices. Critical quantities for Ising systems obtained from the IQC approximation are compared in table 1 with exact or best approximate (B.A.) ones [5,6]:

Table 1. Critical quantities for Ising systems.

In the critical range, the functions $\rho(\tau)$ and $\varphi(\tau)$ can be expressed with the analytic form:

$$
\rho(\tau)=\sum_{i} C_{p i} \cdot(1-\tau)^{a_{i}} \quad ; \quad \varphi(\tau)=\sum_{i} C_{\varphi i} \cdot(1-\tau)^{b_{i}}
$$

The condition for the order parameter of satisfying the equation $\partial \mathrm{F}_{\mathrm{C}} / \partial \eta=0$ for any $\tau$ implies that a relationship between the lowest exponents of $\rho(\tau)$ and $\varphi(\tau)\left(a_{1}\right.$ and $\left.b_{1}\right)$ and the critical exponent $(\bar{\beta})$ of the order parameter $(\bar{\beta}$ equal to $5 / 16$ for $3 D$ and $1 / 8$ for $2 D): a_{1}=b_{1}=2 \bar{\beta}$. The following expressions of $\rho$ and $\varphi$ can be adopted when $(1-\tau)<10^{-4}$;

$$
\begin{aligned}
& \rho=1+c_{\rho 1} \cdot(1-\tau)^{2 \bar{\beta}}+c_{\rho 2} \cdot(1-\tau)+c_{\rho 3} \cdot(1-\tau)^{4 \bar{\beta}}+c_{\rho 4} \cdot(1-\tau)^{2 \bar{\beta}+1}+c_{\rho 5} \cdot(1-\tau)^{6 \bar{\beta}}+c_{\rho 6} \cdot(1-\tau)^{4 \bar{\beta}+1} \\
& \varphi=\varphi_{c r}+c_{\varphi 1} \cdot(1-\tau)^{2 \bar{\beta}}+c_{\varphi 2} \cdot(1-\tau)+c_{\varphi 3} \cdot(1-\tau)^{4 \bar{\beta}}+c_{\varphi 4} \cdot(1-\tau)^{2 \bar{\beta}+1}+c_{\varphi 5} \cdot(1-\tau)^{6 \bar{\beta}}+c_{\varphi 6} \cdot(1-\tau)^{4 \bar{\beta}+1}
\end{aligned}
$$

Since internal energy is a linear function of the $\rho$ and $\varphi$ first derivatives with respect to $\tau$ ( $\rho^{\prime}$ and $\varphi^{\prime}$ ), we must impose constraints between coefficients $C_{\rho i}$ and $C_{\varphi i}[7,8]$, in order to obtain correct values of intemal energy and specific heat.

When the interpolation range is progressively reduced, the first three coefficients of $\rho$ and $\varphi$ slightly varies until "asymptotic" values are approached, when $(1-\tau) \leqslant 10^{-6}$. These values, calculated for different $3 \mathrm{D}$ lattices, are a linear 
function of the coordination number. Some terms of $\rho$ and $\varphi$ expressions, while representing only a small correction in the critical range, become significant for small values of $\tau$ and to extend the expression of $\rho$ and $\varphi$ becomes difficult because of the great number of terms needed.

\section{ORDERING PHENOMENA IN $\beta$-BRASS}

$\mathrm{Cu}-\mathrm{Zn}$ alloys with bcc structure show ordering at $\mathrm{T}<741 \mathrm{~K}$ : fully ordered $\mathrm{Cu}_{0.5} \mathrm{Zn}_{0.5}$ has CsCl-structure(B2). A consistent interpretation of ordering phenomena must take into account data about order parameter and specific heat $\left(C_{p}\right)$. Long range order data, measured by $X$-ray and neutron diffraction experiments $[9,10]$, have been examined and the following interpolating expression of $\eta$ as a function of $\tau$ is proposed:

$$
\eta(\tau)=\left[1.64(1-\tau)^{.2995}+.316(1-\tau)^{.7}+.982(1-\tau)^{5}-.498(1-\tau)^{8}\right] /(1.64+.316+.982-.498)^{(1-\tau)}
$$

The experimental values of the order parameter are given assuming as one the maximum observed value; this could be an approximation and could taken into account with introduction of a normalizing factor. The function $\eta(\tau)$ (with $\eta_{\max }$ $=1$ ) is plotted in fig. 1, together with the calculated values for a bcc Ising system $(z=8)$. The curve of $\beta$-brass is close to that of an Ising lattice with $z$ smaller than 8 and intermediate between curves of 3D and 2D lattices.

In order to obtain an analytic $\mathrm{C}_{\mathrm{p}}(\tau)$ function, experimental values of specific heat [11-13] have been interpolated with the expression:

$$
\begin{array}{lrl}
C_{p} / R=2.48(1-\tau)^{-.11} \cdot e^{8.38(\tau-1)}-2.48 \mathrm{e}^{-8.38}-\tau(1-\tau)^{4}[1.97-2.38(1-\tau)] & \text { for } \tau<1 \\
C_{p} / R=1.68(\tau-1)^{-.11} \cdot e^{-.041(1-\tau)}-1.68 \mathrm{e}^{.041}+(2-\tau)(1-\tau) \cdot[2.86+13.54(1-\tau)] & \text { for } 1<\tau<1.15 \\
C_{p} / R=-.332 \cdot \tau+.614 & \text { for } 1.15<\tau<1
\end{array}
$$

The entropy change $\Delta S=\int\left(C_{p} / T\right) d T$ calculated with this function (and extrapolated linear dependence for $\tau>1.15$ ) is $0.5643 \cdot R$, smaller than the value $\Delta S=R \cdot \ln 2=R \cdot 0.6931$, which take into account the number of configurational states from fully ordered to fully disordered alloys.

The agreement between the specific heat of an ideal Ising lattice and the experimental one is unsatisfactory for $z=8$ and can be improved only with $\mathrm{z}=14$ (the critical quantities in this case are calculated by linear extrapolation).

A specific heat function (labelled as "modified" in fig.2) has been calculated, satisfying energy and entropy changes, consistent with the critical quantities for $z=14$ and the condition $\Delta S=R \cdot \ln 2$ :

$$
C_{p} / R=2.106 \cdot(1-\tau)^{-.11} \cdot e^{13.28(\tau-1)}-2.106 \mathrm{e}^{-13.28}-\tau \cdot[.847-1.095(1-\tau)] \quad \text { for } \tau<1
$$

This function differs from the experimental one mainly in the low temperature range: this discrepancy is justified taking
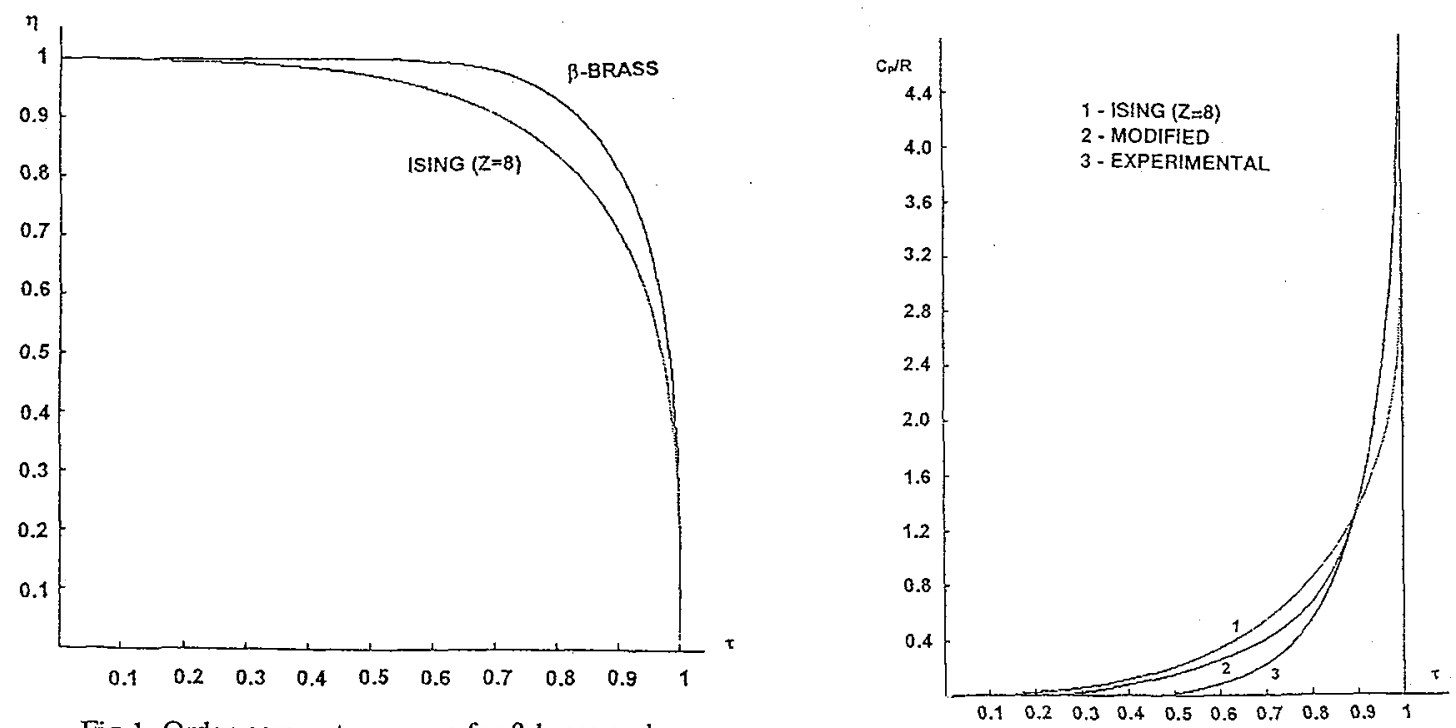

Fig.1. Order parameter curves for $\beta$-brass and bcc Ising systems.

Fig.2. Comparison of specific heat functions. 


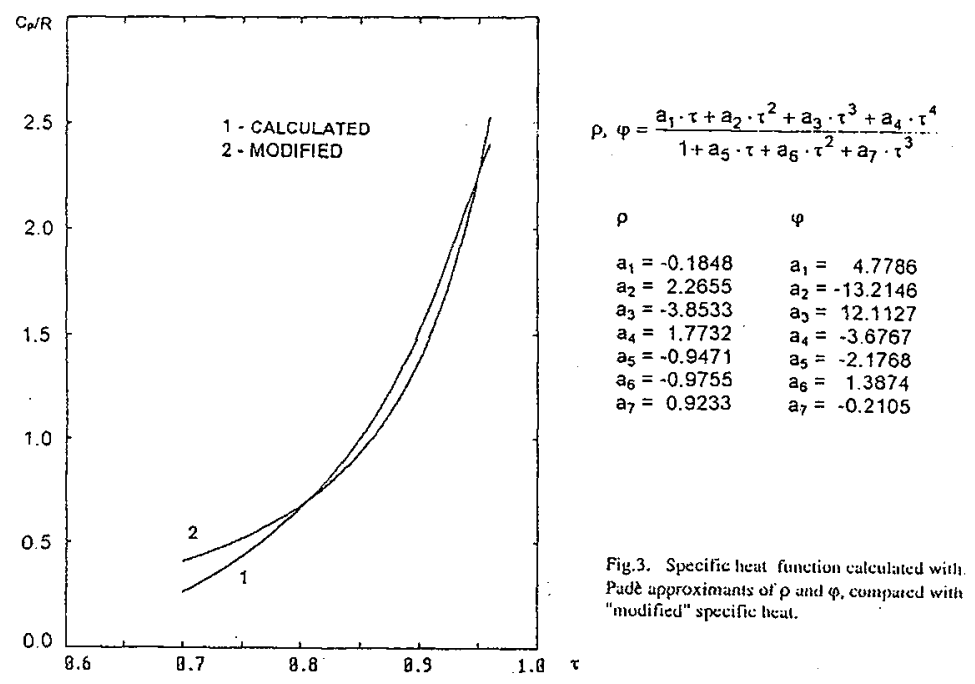

into account the difference of $\Delta S$ as a consequence of the "weighing" function $1 / T$ in the integral. This observation agrees with the Inden hypothesis [14], suggesting that order equilibrium states are not achieved at low temperature.

IQC approximation has been applied to describe a system with these properties: $z=14$, specific heat function equal to the "modified" one and order-parameter curve coincident with the experimental one, with $\eta_{\max }=1$. Functions $\rho$ and $\varphi$ have been calculated and they can be written in analytic form by a ratio of polynomials (Padè-approximants) in the temperature range $0.7<\tau<0.94$.

Specific heat calculated from these expression is compared in fig. 3 with the "modified" one. Under the hypothesis that the experimental specific heat is measured in a system constrained at low temperature, the fully ordered state would not be obtained by the system and this could justify why $\Delta S$ is lower than $R \cdot \operatorname{In} 2$. By counting the number of configurational states, for $\Delta S=0.5643 \cdot \mathrm{R}$ a $\eta_{\max }$ value of 0.9434 is obtained. A system with this value of $\eta_{\max }$, with experimental specific heat and ordered parameter functions has been considered with the IQC approximation but, the description of this system by the Ising model is not possible, because the critical quantities cannot be matched. Hence, Ising model systems, even changing the coordination number, cannot be suited to give a full and consistent description of ordering behaviour for $\beta$-brass. The description is possible if only partial agreement with experimental data is admitted, ascribing it to constraints coming from difficult relaxation at low $\tau$.

The order degree corresponding to the lowest temperature of substantial coincidence between experimental and "modified" specific heat curves is $\eta \approx 0.88$, which is comparable to the calculated $\eta_{\max }=0.9434$. This would indicate that the maximum order degree attained in the constrained system is close to 1 . To. assume, for obtaining suitable phase boundaries in $\mathrm{Cu}-\mathrm{Zn}$ phase diagram, that $\eta_{\max }=0.64$, indipendently of the system composition [15], is far from the experimental evidence.

\section{REFERENCES}

[1] CAVALLOTTI P. L.,BERGAMASCHI R., OSSI P. M., Mat.Sci.Tech. 3 (1985) 46.

[2] CAVALLOTTI P. L., NOBLLI L., OSSI P.M., COLOMBI B., COLOMBO M., I.Mag.MKat. 83 (1990) 100.

[3] CAVALLOTTI P. L., NOBILI L., OSSI P.M., Key Ing.Mat. 48 (1990) 47.

[4] GUGGENHEIM E.A., Mixtures, Oxford, (1952).

[5] FISHER M.E., Rep.Pro.Phys. 30 (1968) 615.

[6] DOMB C., in Phase Transition and Critical Phenomena, vol 3, p. 357, Domb C., Green M.S. (eds.), Academic Press, (1971)

[7] CAVALLOTTI P. L., ALBERTI M., BOZZINI B., IUDICA A., NOBILI L., OSSI P.M., in Ordering and Disordering in Alloys, p.229, Yavari A.R. (ed.), Elsevier Applied Science, (1991).

[8] CAVALLOTTI P. L., ALBERTI M., BOZZINI B., IUDICA A., NOBILI L., OSSI P.M., g.MagaMat., 104-107 (1992) 105.

[9] CHIPMAN D.R., WALKER C.B., Phys.Rev. 85 (1972) 3823.

[10] RATHMANN D., ALS-NIELSEN J., Phys.Rev. 89 (1974) 3921.

[11] MOSER H., ThysikZ.37 (11936) 737.

[12] SYKES C., WILKINSON H., g.inst.Mket. 61 (1937) 223.

[13] ASHMANN J., HANDLER P., Pfys Rev.Lett. 23 (1969) 642.

[14] INDEN G., Z.Metalfkunde 66 (1975) 648.

[15] ZHOU XIAOWANG, HSU T.Y., Acta Met. 37 (1989) 3085. 